\title{
X-ray Inspection of MIM 418 Superalloy Turbine Wheels and Defects Analysis
}

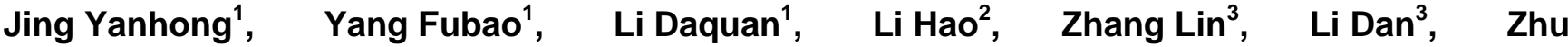 \\ Qiang ${ }^{1}$
}

${ }^{1}$ General Research Institute for Nonferrous Metals, Beijing 100088, China; ${ }^{2}$ Beijing Special Equipment Inspection \& Testing Center, Beijing 100029, China; ${ }^{3}$ Beijing University of Science and Technology, Beijing 100083, China;

\begin{abstract}
Turbine wheels produced by metal injection molding (MIM) were subjected to X-ray inspection using three different $\mathrm{X}$-ray instruments, including film X-ray, real-time imaging X-ray and microfocus X-ray. One of the X-ray inspected turbine wheels was then cut and polished for defects observation using optical microscope (OM) and scanning electron microscope (SEM) equipped with an energy dispersive X-ray spectrometer (EDS). The defects existing in the blades and the center of the turbine wheels were analyzed using an analysis software. The results show that under the same testing condition, the film X-ray equipment has higher sensitivity than the real-time imaging X-ray. However, the microfocus X-ray testing is not suitable to the MIM418 turbine wheels due to low power. Nondestructive testing (NDT) and metallographic observation reveal that macro-cracks are prone to forming in the center part of the turbine wheel, and the micro-defects in term of porosity in the blade are more than in the center of the sintered turbine wheel. Although heat isostatic pressing (HIP) can significantly decrease the porosity, cracks are not healed.
\end{abstract}

Key words: metal injection molding; turbine wheel; superalloy; X-ray inspection

Metal powder injection molding (MIM) is a powder metallurgy process, which combines the advantages of the plastic injection molding with the versatility of the traditional powder metallurgy. The process has four steps: mixing powder with binder, injection molding, debinding and sintering. The process overcomes the shape limitation of traditional powder compaction, and saves the high cost of machining. Comparing with casting, the almost casting defects free, fine microstructure and excellent mechanical property can be obtained $^{[1-4]}$.

The turbine wheel is a key part in turbochargers, having complex shape and determining life of a turbocharger, efficiency of energy consumption and reduction of emission. Superior properties are required because of the service condition at high temperature and cyclic speeds (therefore stresses). These characters make MIM a potential technical application in producing turbine wheels ${ }^{[2]}$. In view of the requirement of high performance, superalloy K418 was selected to be the base material of turbines due to its high temperature strength, good fatigue resistance and good corrosion resistance ${ }^{[5]}$. However, casting defects in the investment cast turbine wheel restrict the application of the alloy. Therefore, taking these characteristic into consideration, MIM becomes a preferred candidate to produce turbine wheels, because the products with complex geometric design, minimum material loss, significantly cost saving and almost casting defects free can be manufactured.

Unfortunately, in MIM process, binder is $30 \mathrm{vol} \% \sim 40$ vol\% usually in order to achieve good rheological property $^{[6]}$. Defects related with the binder are easily formed due to the significant volume shrinkage. In the present paper, a nondestructive testing technique (NDT)

$\overline{\text { Received date: February 14, }}, 2016$

Foundation item: National High Technology Research and Development Program of China ("863" Program) (2012AA03A514)

Corresponding author: Jing Yanhong, Master, General Research Institute for Nonferrous Metals, Beijing 100088, P. R. China, Tel: 0086-10-60680138, E-mail: yhjing10s@alum.imr.ac.cn

Copyright (C) 2017, Northwest Institute for Nonferrous Metal Research. Published by Elsevier BV. All rights reserved. 
was employed to detect the defects in turbine wheels produced by MIM, and metallurgy observation was applied to analyze nature of defects. This can accumulate the experimental data aiming to optimize the production process for MIM418 turbine wheels.

\section{Experiment}

In this experiment, 8 turbine wheels produced by metal injection molding (MIM) were investigated. All turbine wheels were subjected to powder preparation, injection molding, debinding, sintering, and then heat isostatic pressing (HIP). Superalloy powders were mixed with the binder consisting of $60 \%$ paraffin wax $(\mathrm{PW})+15 \%$ high density polyethylene (HDPE) $+15 \%$ polypropylene $(\mathrm{PP})+$ $10 \%$ stearic acid (SA) to produce the feedstock with excellent rheological property at $160{ }^{\circ} \mathrm{C}$. The sintering was conducted at $1240{ }^{\circ} \mathrm{C}$ in vacuum and HIP was $1210^{\circ} \mathrm{C}$ under argon atmosphere.

All sintered turbine wheels were selected from the same batch and tested using XXQ-2505 film X-ray equipment with $\Phi 2 \mathrm{~mm}$ focus. The samples were marked as No.1, 2, 3, 4, 5, 6, 7 and 8. The large thickness difference, e.g. the thinnest site at blade is about $2 \mathrm{~mm}$, and the thickest part at the center part is about $30 \mathrm{~mm}$, can produce a big film density difference, and an edge corrosion effect, which can result in sensitivity failure ${ }^{[5]}$. Therefore, blade and center parts were tested separately adopting different process parameters. Because the blade was thin, the voltage was set to be $150 \mathrm{kV}$, and then the voltage was up to $230 \mathrm{kV}$ for the center in order to penetrate the center part of the turbine wheel. The other testing parameters were the same for all conditions, i.e. $5 \mathrm{~mA}$ current, $3 \mathrm{~min}$ time duration and 900 $\mathrm{mm}$ focus distance. In order to decrease misdetection rate, the turbine wheels were detected along $X, Y$ and $Z$ axis directions as shown in Fig.1.

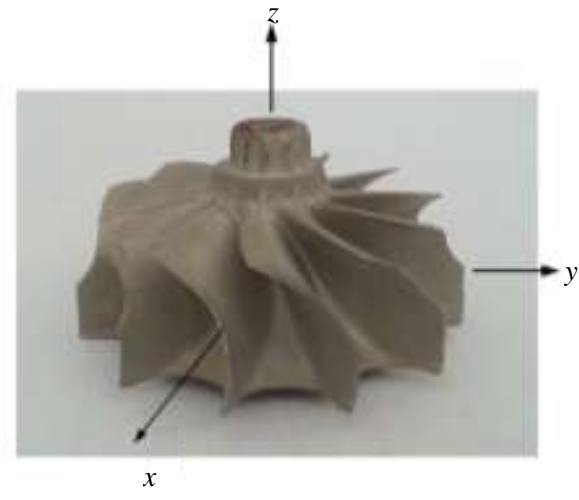

Fig.1 Transillumination direction of X-ray inspection

A typical turbine wheel was cut into half along the center line. One part was just sintered, and the other was sintered and HIPed. Microstructures of the two parts were observed using optical microscope (OM) and scanning electron microscope (SEM) under different process conditions and in various areas. The defects in the MIM turbine wheels were statistically analysis using a MIM TAB software.

\section{Results and Discussion}

The testing results are shown in Table 1. It can be seen from this table that the transillumination direction has great effect on the detection ratio of crack, which is consistent with the observation by Tie et $\mathrm{al}^{[7]}$. In addition, the result reveals that the crack exist in all turbine wheels using XXQ-2505, but only is found in No.2 and No.4 turbine wheels using CDZ-302P-A. These results indicate that the film X-ray testing sensitive than the real-time imaging under the same condition. The testing results obtained using microfocus X-ray equipment are given in Fig.2. Some gas pores can be seen obviously from the blades of the both turbine wheels, as marked by red circles. No defect is found

Table 1 Inspection results of MIM418 by XXQ-2505 and CDZ-302P-A

\begin{tabular}{|c|c|c|c|}
\hline \multirow{2}{*}{ Sample No. } & \multicolumn{2}{|l|}{ XXQ-2505 } & \multirow{2}{*}{ CDZ-302P-A } \\
\hline & $X$ & $Y, Z$ & \\
\hline 1 & 2 gas pores $(\Phi 0.5 \mathrm{~mm} \times 2)$ existing in blade & $3 \mathrm{~mm}$ crack & 2 gas pores $(\Phi 0.5 \mathrm{~mm} \times 2)$ existing in blades \\
\hline 2 & $\begin{array}{c}4 \text { cracks existing in center part(the length each crack } \\
\text { is about } 15 \mathrm{~mm}) ; 4 \text { gas pores }(\Phi 0.5 \mathrm{~mm} \times 3, \Phi 1.0 \\
\mathrm{mm} \times 1) \text { existing in blades }\end{array}$ & $7 \mathrm{~mm}$ crack & $\begin{array}{l}2 \text { cracks (the length is } 25 \mathrm{~mm} \text { and } 6 \mathrm{~mm} \text {, } \\
\text { respectively) existing in center, } 3 \text { gas pores } \\
\text { existing in blades }\end{array}$ \\
\hline 3 & 2 gas pores $(\Phi 1.0 \mathrm{~mm} \times 2)$ existing in blades & $7 \mathrm{~mm}$ cracks $\times 2$ & 1 gas pores $(\Phi 0.5 \mathrm{~mm})$ existing in blades \\
\hline 4 & $\begin{array}{l}\text { Two cracks (the length is about } 15 \mathrm{~mm} \text { ) existing in } \\
\text { the center part }\end{array}$ & $7 \mathrm{~mm}$ crack & Two cracks $(15 \mathrm{~mm} \times 2)$ existing in the center \\
\hline 5 & 1 crack $(15 \mathrm{~mm})$ existing in the center part & $10 \mathrm{~mm}$ crack & No defect sign \\
\hline 6 & $\begin{array}{c}1 \text { crack }(5 \mathrm{~mm}) \text { existing in the center part, } 1 \text { gas pore } \\
(\Phi 1.0 \mathrm{~mm}) \text { existing in the blade }\end{array}$ & $5 \mathrm{~mm}$ crack & 1 gas pore $(\Phi 0.5 \mathrm{~mm})$ existing in the blade \\
\hline 7 & $\begin{array}{c}1 \text { crack }(5 \mathrm{~mm}) \text { existing in the center part, } 1 \text { gas pore } \\
(\Phi 1.0 \mathrm{~mm}) \text { existing in the blade }\end{array}$ & No defect sign & No defect sign \\
\hline 8 & $3 \mathrm{~mm}$ linear existing in blade & $4 \mathrm{~mm}$ crack & No defect sign \\
\hline
\end{tabular}

Note: gas pore $\Phi 0.5 \mathrm{~mm} \times 2$ means that the pore size is $\Phi 0.5 \mathrm{~mm}$, and the number of pore is 2 ; the linear defect forms due to separation between metal powder and binder 


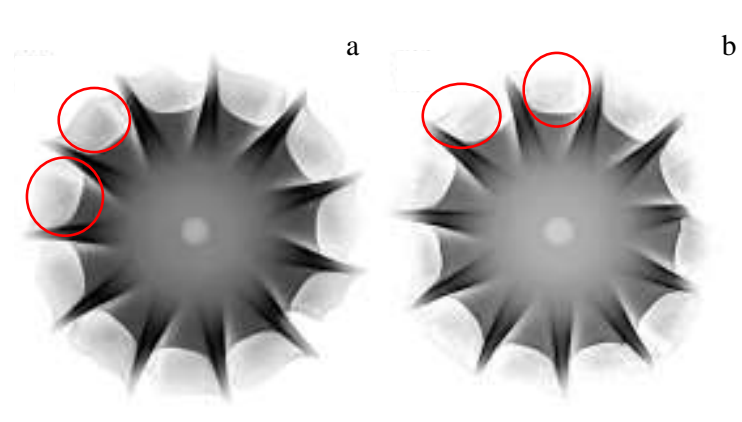

Fig.2 X-ray inspection results of MIM turbine using microfocus equipment: (a) injection molding turbine wheel and (b) sintered turbine wheel

in the center site of turbine wheels, which arises from the $0.2 \mathrm{~mA}$ low currency, even though the microfocus X-ray equipment has very high resolution. As a result, defects in the center part of samples can't be found due to underexposure.

It is well known that cracks are the most serious defect in MIM productions for mechanical properties such as fatigue. However, it is difficult to find all cracks through X-ray inspection. This is because the crack is a two dimensional defect. Crack width, radiograph angle and the sample thickness are all the key parameters affecting inspection results. Only when the crack width $(W)$ is bigger than a critical value $\left(W^{\prime}\right)$, it is possible to detect the crack. According to Eq.(1) ${ }^{[5]}$, the critical value $W^{\prime}$ is $0.12 \mathrm{~mm}$ for XXQ-2505 type X-ray equipment $\left(L_{1}+L_{2}=900 \mathrm{~mm}, d_{\mathrm{f}}=2\right.$ $\left.\mathrm{mm}, L_{2}=52 \mathrm{~mm}\right)$.

$$
W^{\prime}=d_{\mathrm{f}} L_{2} /\left(L_{1}+L_{2}\right)
$$

where, $d_{\mathrm{f}}$ is the diameter of the focus, $L_{1}$ is the distance from the focus to the defect, and $L_{2}$ is the distance from the defect to the film. When the transmission direction and the crack are at the same direction, detection of the defects is the easiest, otherwise the defect is difficult to detect. Because the crack direction in MIM turbine is uncertain, it is easy to miss cracks during X-ray inspection. In addition, thickness of the inspected sample has great effect on the crack detection ratio. When it increases, the scattering ratio $(n)$ increases too, and contrast $(\Delta D)$ decreases according to Eq.(2), while geometric unsharpness $\left(U_{\mathrm{g}}\right)$ and inherent unsharpness $\left(U_{\mathrm{g}}\right)$ increase according to Eq.(3) and (4). All these parameters decrease the crack detection ratio ${ }^{[5]}$. Therefore, defects in the thin part are easier to find than that in the thick part. These can also explain why the gas pore defect in blade is detected but not in the center part.

$$
\begin{aligned}
& \Delta D=0.434 \mu G \Delta T /(1+n) \\
& U_{\mathrm{g}}=d_{\mathrm{f}} L_{2} / L_{1} \\
& U_{\mathrm{i}}=0.0013(\mathrm{kV})^{0.79}
\end{aligned}
$$

where $\mu$ is the attenuation coefficient, $G$ is the film gradient, $\Delta T$ is the defect scale along transmission direction and $\mathrm{kV}$

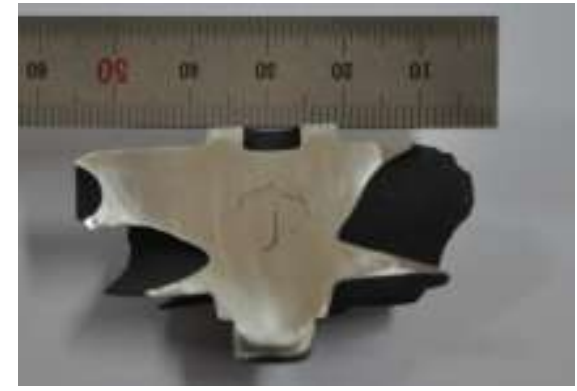

Fig.3 Sectional image of the sintered turbine

is the detection voltage. When a turbine wheel is cut into half, two cracks with sizes of about $10 \mathrm{~mm}$ in length and $0.3 \mathrm{~mm}$ in width are observed at the center part, as shown in Fig.3. After HIP, the both cracks have no healing sign. This is not consistent with the results of Zhao et $\mathrm{al}^{[8]}$. This may arise from different crack widths in the two investigations. The critical powder loading for injection molding is 65 vol\% 67 vol\%, which potentially lead to significant shrinkage. The previous experiment revealed that the volume shrinkage is $12.7 \%$ after sintering due to loss of binder ${ }^{[9]}$. The center part is about $52 \mathrm{~mm}$ in thickness, which is very different from that of the center part of the blade. These characters make stress distribution nonuniform within the turbine wheel at the center part. Thus, during sintering, tensile stress is evoked at the center part, which leads to crack. For the blade, the specific surface area is larger and the shrinkage is more homogeneous, so no cracks form in the blade.

Fig.4 presents SEM morphology and EDS analysis of the crack formed in sintered and HIPed turbine wheels. EDS detects oxygen and carbon, indicating oxides existing on the crack surface, and residual of the binder. This is concluded as the sintering process is in vacuum $\left(10^{-1} \mathrm{~Pa}\right)$. The metal powder contains $\mathrm{Al}$ and $\mathrm{Ti}$, which is sensitive to oxygen and carbon. When sintering, it is relatively difficult to volatilize out in thick position which accelerate the oxidation and formation of crack. Once the crack forms with oxide, the following process can't eliminate the defects, and this can lead to MIM product failure directly.

$\mathrm{OM}$ investigations indicate that the sintered sample has a high level of porosity, and the porosities are almost spherical, as shown in Fig.5. After HIP, density of the porosity decreases significantly, even almost disappears. This result is consistent with the mass density inspection for the samples before and after HIP. The relative density is 95\% before HIP and then increases up to 97\% after HIP. 10 photos taken from the samples after sintering were subjected to statistical analysis. The results reveal that the defect area fraction of the center site is about $0.31 \%$, and that of the blade is about $0.48 \%$. 

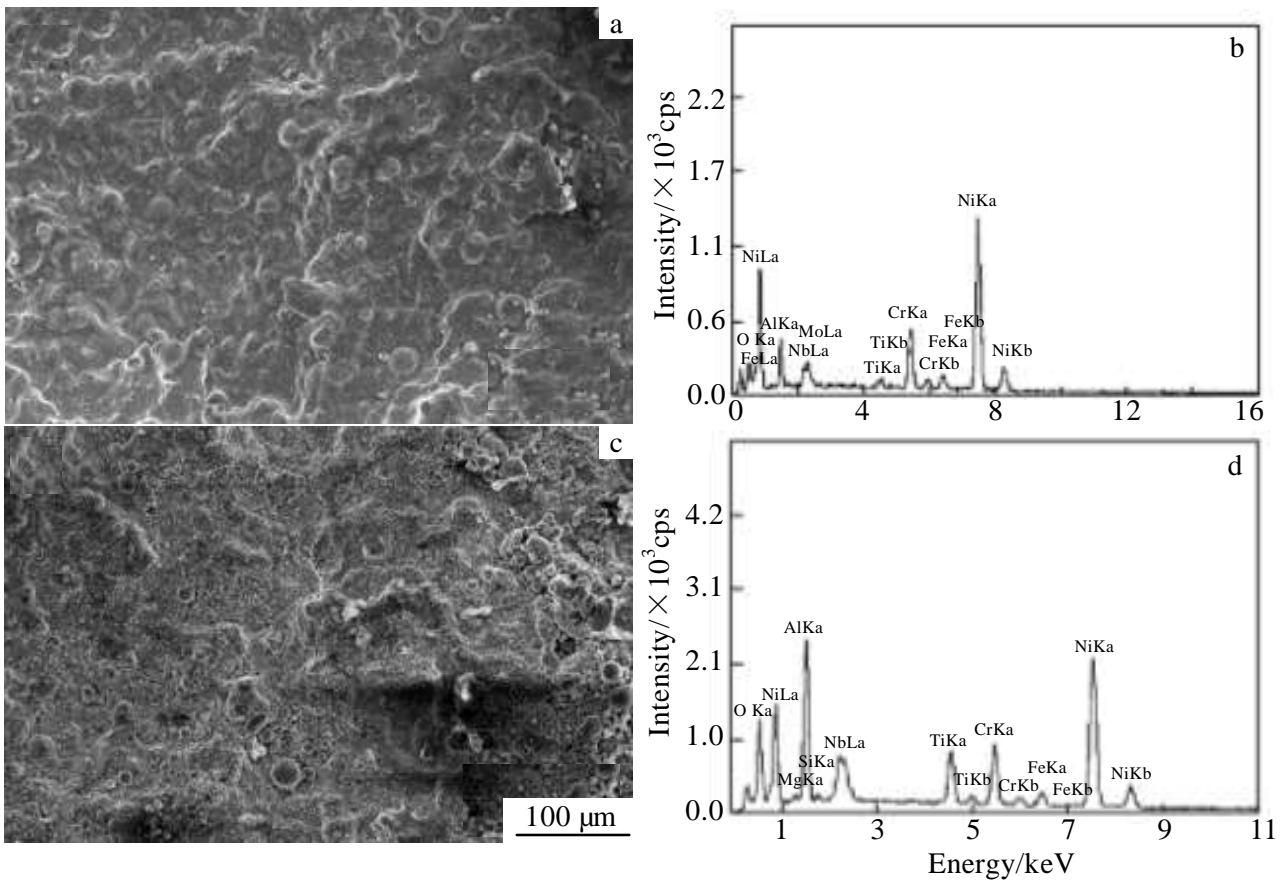

Fig.4 SEM morphologies (a, c) and EDS spectra (b, d) of the crack surface at center of turbine wheel: as MIMed (a,b) and as HIPed (c, d)

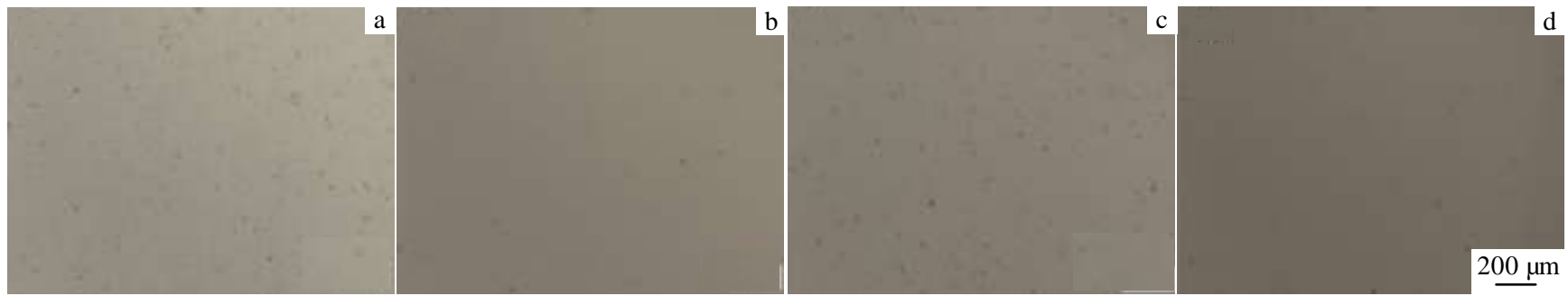

Fig.5 OM images of the samples taken from MIM turbine wheels: (a) center site of the sintered sample, (b) center of the sintered \& HIPed sample, (c) blade of the sintered sample, and (d) blade of the sintered \& HIPed sample
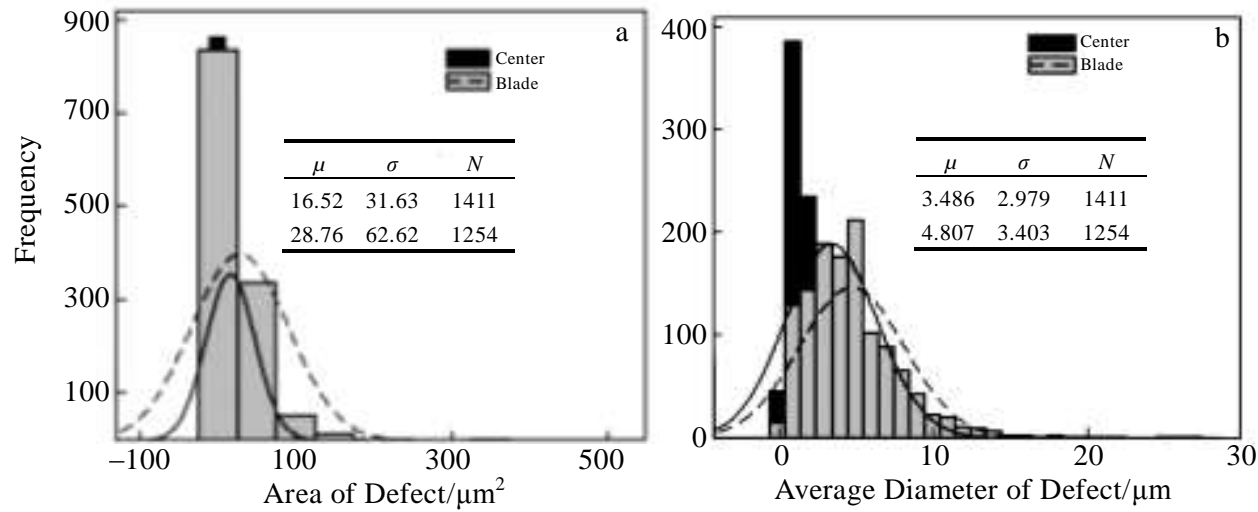

Fig.6 Statistical analysis of defects in sintered sample: (a) defect area and (b) average diameter of defect ( $\mu$-average; $\sigma$-standard deviation; $N$-amount of defects)

The size and area distribution of defects are shown in Table 2 and Fig.6. It can be seen that the blade has higher porosity than the center, and the defect in blade is slightly larger than that in the center. It is worth noting that some defects are very large in the blade (Fig.7), but the very large defects are not found in the center. The nature of defect distribution difference in the center and blades is attributed to two reasons. Firstly, slight separation can occur between 
Table 2 Statistical results of defects existing in MIM turbines

\begin{tabular}{cccc}
\hline Defect size & Average & Max & Focus range \\
\hline Area of center $/ \mu \mathrm{m}^{2}$ & 16.5 & 354.7 & $1.2 \sim 19.8$ \\
Area of blade/ $\mu \mathrm{m}^{2}$ & 28.8 & 1132.2 & $5.7 \sim 34.1$ \\
Mean diameter of center $/ \mu \mathrm{m}$ & 3.5 & 21.3 & $1.3 \sim 4.9$ \\
Mean diameter of blade $/ \mu \mathrm{m}$ & 4.8 & 32.3 & $2.6 \sim 6.2$ \\
\hline
\end{tabular}

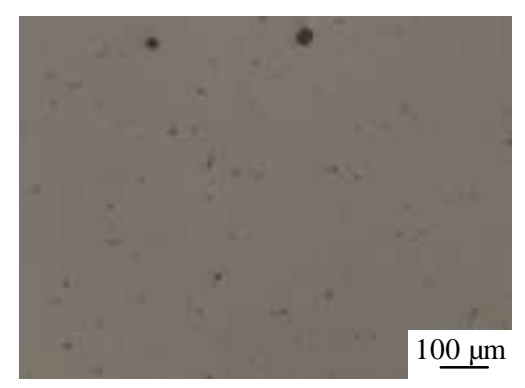

Fig.7 Abnormal defect existing in blade after sintering

the metal powder particle and the binder, resulted from frictional force between powder particle, binder and mold. This kind of separation is more serious than that in the blade, which can lead more binder and less metal powder to inject into the blade, so more pores and very large defects are formed, compared with the center part. The other reason is that fluid front is easier to entrap gas, and then flows into the blade during injection molding process, which is verified by $\mathrm{X}$-ray inspection.

\section{Conclusions}

1) Under the same condition, the film $X$-ray equipment has higher resolution than the real-time imaging X-ray. Microfocus X-ray testing is not suitable to the MIM418 turbine because the center part is thick (about $30 \mathrm{~mm}$ ).
Although the microfocus X-ray equipment has high voltage that can penetrate the turbine, the low current will lead to underexposure.

2) Macro-cracks are prone to forming in the center part of the sintered turbine, because the center part is thick which can lead to uneven shrinkage during the debinding process.

3) The porosity of the blade is higher than that of the center part in the sintered turbine. And abnormal gas defects in blade is more (larger size) than that in the center part due to separation between the metal powder and binder during the injection molding process, and the abnormal large defects can't heal after sintering.

\section{References}

1 Zhang C, Hu J J, Cheng D T. Modern Manufacturing Engineering [J], 2004(1): 51 (in Chinese)

2 Huang Boyun. Powder Metallurgy[M]. Beijing: Metallurgical Industrial Press, 2011: 7 (in Chinese)

$3 \mathrm{Hu} \mathrm{Y,} \mathrm{Li} \mathrm{Y} \mathrm{M,} \mathrm{He} \mathrm{H}$ et al. Rare Metal Materials and Engineering $[\mathrm{J}], 2010,39(5): 775$

4 Peng Z C, Xie F Q, Zhang J et al. Rare Metal Materials and Engineering[J], 2013, 42(10): 1988

5 Jiang Tianpeng. X-ray Inspection[M]. Beijing: China Laboratory \& Social Security Publishing House, 2007: 75, 83, 129 (in Chinese)

6 Flemings, Merton C. Metallurgical Transactions B[J], 1991, 22(3): 269

7 Tie Qiang, Chen Zhidong. Pipeline Technology and Equipment [J], 2009, 4: 51

8 Zhao X M, Lin X, Chen J et al. Materials Science and Engineering $A[\mathrm{~J}], 2009,504: 129$

9 Yang F B, Jing Y H, Li D et al. Rare Metal[J], 2015, 38(1): 5

\title{
MIM418 涡轮的射线检测及其缺陷分析
}

\author{
景艳红 ${ }^{1}$, 杨福宝 ${ }^{1}$, 李大全 ${ }^{1}$, 李 浩 $^{2}$, 章 琳 $^{3}$, 李 丹 $^{3}$, 朱 强 $^{1}$ \\ (1. 北京有色金属研究总院, 北京 100088) \\ (2. 北京特种设备检测中心, 北京 100029) \\ (3. 北京科技大学, 北京 100083)
}

\begin{abstract}
摘 要: 采用不同的 X 射线设备对注射成形的 MIM418 浴轮进行检测, 并对缺陷进行了解剖, 采用光学显微镜(OM)和扫描电镜(SEM) 观察其形貌, 由 EDS 确定其成分, 采用 MIM TAB 软件对涡轮不同部位的缺陷进行了统计分析, 并研究了热等静压 (HIP) 对缺陷的影 响。研究结果表明: 胶片 $X$ 射线设备比实时呈像具有更高的检测灵敏度, 微焦点射线设备, 不适用于 MIM 418 浴轮的检测, X 射线检 测和缺陷形貌观察表明在浴轮心部易于形成裂纹, 相对于心部, 在叶片处的气孔型缺陷更多一些, 采用 HIP 可大幅度降低气孔型缺陷, 但裂纹并不能愈合。
\end{abstract} 关键词: 金属粉末注射成形; 浴轮; 高温合金; X 射线检测 